\title{
A Review on Sublingual Tablets
}

Prathusha $\mathbf{P}^{1 *}$ and Praneeth Kamarapu ${ }^{2}$

${ }^{1}$ Browns College of Pharmacy, Khammam, Telangana, India

${ }^{2}$ Department of Pharmaceutical Sciences, The University of Greenwich, London, UK

\begin{abstract}
Drug delivery through the oral mucous film is considered to be a promising contrasting option to the oral course.

Sublingual course is a quick onset of activity and preferred patient consistence over orally ingested tablets. Sublingual (contracted SL), from the Latin for "under the tongue", alludes to the pharmacological course of organization by which drugs diffuse into the blood through tissues under the tongue. Sublingual course is a valuable when fast onset of activity is wanted with preferable patient consistence over orally ingested tablets. Regarding penetrability, the sublingual al range of the oral pit (i.e. the floor of the mouth) is more porous than the buccal (cheek) range, which thusly is more penetrable than the palatal (top of the mouth) territory.
\end{abstract}

Keywords: Sublingual rout; Mucous; Tablets; Tongue

\section{Introduction}

Sublingual drug delivery (SL) of the medication implies arrangement of the medication under the tongue and drug comes to straightforwardly into the circulation system through the ventral surface of the tongue and floor of the mouth. The fundamental system for the retention of the medication into oral mucosa is by means of latent dissemination into the lipoidal film. The retention of the medication through the sublingual course is 3 to 10 times more prominent than oral course and is just surpassed by hypodermic infusion. For these details, the little volume of spit is generally adequate to bring about tablet crumbling in the oral cavity [1-5].

This course has a few particular points of interest over the enteral and parenteral courses of medication conveyance because of its rich blood supply, quick onset of activity, improved bioavailability, shirking of the principal pass and sustenance impacts, expanded patient consistence, and simplicity of self-solution. Throughout the years, various items exploiting oral mucosal medication conveyance have been presented in the business sector [6-10].

Drugs accessible as sublingual tablets are Isosorbide dinitrate, Nitroglycerin, Fentanyl citrate, Buprenorphine hydrochloride, Ergotamine tartrate, Ergoloid mesylates, Asenapine (Saphris), Buprenorphine hydrochloride and naloxone hydrochloride, Zolpidem tartrate (Intermezzo) and many more drugs [11-20].

Any type of substance might be managable to sublingual organization on the off chance that it breaks down effectively in spit. Powders and vaporizers may all exploit this technique. In any case, various components, for example, $\mathrm{pH}$, molecular weight, and lipid solubility, may figure out if the course is down to earth. In view of these properties, an appropriately solvent medication may diffuse too gradually through the mucosa to be powerful. Be that as it may, numerous medications are significantly more strong taken sublingually, and it is for the most part a more secure option than organization by means of the nasal mucosa. This strategy is additionally broadly utilized by individuals regulating certain psychoactive medications. One disadvantage, in any case, is tooth staining and rot brought about by long haul utilization of this technique with acidic or generally burning medications and fillers [21].

1. Passive diffusion

2. Active or carrier-mediated transport

3. Endocytosis

\section{Factors affecting the sublingual absorption}

1. Lipid solubility of drug

2. Saliva $\mathrm{pH}$ and $\mathrm{pKa}$

3. Oral epithelium thickness

4. Partition coefficient

\section{Methods of Preparation}

Following methods can be used to prepare sublingual tablets

1. Direct compression Method

2. Compression molding

3. Freeze-drying

\section{Direct compression method}

This is a commonly used method for preparation of sublingual dosage forms and it is a simple and most economical method. Direct compression Method is best suitable for heat labile drugs. In this method we are using direct compressible and soluble ingredients, lubricant and a superdisintegrant (for example Crospovidone, Micro crystalline cellulose etc.), dry binder, sweeteners and flavors [22-24].

\section{Compression molding}

Tablets produced by this method will disintegrate and dissolved rapidly (within 4 to $11 \mathrm{sec}$ ). Disadvantage of this method is tablets having poor mechanical strength, to overcome this problem binders are added to formulation blend.

\section{Freeze-drying}

This is costly and consumes more time compared to direct

*Corresonding author: Prathusha P, Browns College of Pharmacy, Khammam Telangana, India, Tel: (087422) 82799; E-mail: prathusha_p10@rediffmail.com

Received January 25, 2017; Accepted February 09, 2017; Published February 15,2017

Citation: Prathusha P, Kamarapu P (2017) A Review on Sublingual Tablets. J Formul Sci Bioavailab 1: 103

Copyright: (c) 2017 Prathusha P, et al. This is an open-access article distributed under the terms of the Creative Commons Attribution License, which permits unrestricted use, distribution, and reproduction in any medium, provided the original author and source are credited. 
compression; this method produces tablets of poor mechanical strength. Tablets produced by this method will have high porosity and dissolve instantly. This method is suitable for heat sensitive drugs.

\section{Evaluation Tests}

\section{Hardness test}

The hardness of the tablets was determined by using Hardness testers like Electro lab hardness tester, Monsanto hardness tester. The tablets should be resistance to breakage under storage conditions.

\section{In-vitro dispersion time}

This test can be done by taking $50 \mathrm{ml}$ of Phosphate buffer $\mathrm{pH} 6.8$, three tablets were tested from each batch and note the dispersion time.

\section{Wetting time}

Place the tablet at the center of absorbent paper fitted into a petridish, After the paper was completely wetted with refined water, overabundance water was totally depleted out of the dish. The time required for the water to diffuse from the wetted retentive paper all through the entire tablet was then recorded utilizing a stopwatch.

\section{Friability}

Roche friabilator can be utilized to decide the friability. Check the weight of tablets and place them in friabilator, The tablets were pivoted in the friabilator for no less than 4 minutes. At the end of test tablets were cleaned and reweighed, the misfortune in the heaviness of tablet is the measure of friability.

Friability is calculated in percentage using following equation

$$
\% \text { Friability }=\frac{\text { Loss in weight }}{\text { Initial weight }} \times 100
$$

\section{In-vitro disintegration test}

This test can be performed by using USP disintegration apparatus, distilled water was used as medium.

The time required to obtain complete disintegration of all tablets was noted.

\section{In-vitro dissolution test}

This test can be performed by using USP dissolution test apparatus type II, $500 \mathrm{ml}$ of distilled water was taken as a dissolution medium, samples were collected at predetermined time intervals and analyze the collected samples using HPLC.

\section{Conclusion}

Sublingual medication conveyance has been utilized for definition of numerous medications with perspective purpose of fast medication discharge and speedy onset of activity. Sublingual items were produced to defeat the trouble in gulping ordinary tablet, among pediatric, geriatric furthermore, psychiatric patients with dysphagia. Compared to regularly utilized tablets, cases and other oral measurements shapes, sublingual absorption is by and large much quicker and more effective. Therefore sublingual tablets are an accepted technology for systemic delivery of drugs.

\section{References}

1. Pistiki A, Galani I, Pyleris E, Barbatzas C, Pimentel M, et al. (2014) In vitro activity of rifaximin against isolates from patients with small intestinal bacterial overgrowth. Int J Antimicrob Agents 43: 236-241.
2. Mantry PS, Munsaf $S$ (2010) Rifaximin for the treatment of hepatic encephalopathy. Transplant Proc 42: 4543-4547.

3. Rivkin A, Gim S (2011) Rifaximin: New Therapeutic Indication and Future Directions. ClinTher 33: 812-827.

4. Zhang X, Duan J, Li K, Zhou L, Zhai S (2007) Sensitive quantification of rifaximin in human plasma by liquid chromatography-tandem mass spectrometry. J Chromatogr B 850: 348-355.

5. Valentin T, Leitner E, Rohn A, Zollner-Schwetz I, Hoenigl M, et al. (2011) Rifaximin intake leads to emergence of rifampin-resistant staphylococci. J Infect 62: 34-38

6. Mullen KD, Sanyal AJ, Bass NM, Poordad FF, Sheikh MY, et al. (2014) Rifaximin is safe and well tolerated for long-term maintenance of remission from overt hepatic encephalopathy. ClinGastroenterolHepatol 12: 1390-1397.

7. Ruiz J, Mensa L, O’Callaghan C, Pons MJ, González A, et al. (2007) In vitro antimicrobial activity of rifaximin against enteropathogens causing traveler's diarrhea. DiagnMicrlnfec Dis 59: 473-475.

8. Jiang Z, Ke S, Dupont HL (2010) Rifaximin - induced alteration of virulence of diarrhoea producing Escherichia coli and Shigellasonnei. Int J Antimicrob Agents 35: 278-281.

9. Castro R, Domenichelli V, Lorenzo FPL, Prestipino M, Perrotta ML (1998) Rifaximin treatment for acute recurrent diarrhea in children with genitourinary disorders. CurrTherap Res 59: 746-752.

10. World Health Organization (2014) Antimicrobial Resistance: global report on surveillance, WHO Press: Geneva.

11. FDA (2015) Food and drug administration department of health and human services sub chapter-D-Drugs for human use, title 21: 5 .

12. FDA (2015) Food and drug administration department of health and human services sub chapter a-general title 21.

13. (2010) Australian government department of health and ageing. Compliance medicines working group report to pharmaceutical benefits advisory committee.

14. Llibre JM, Arribas JR, Domingo P, Gatell JM, Lozano F, et al. (2011) Clinical implications of fixed-dose coformulations of antiretrovirals on the outcome of HIV-1 therapy. AIDS 25: 1683-1690.

15. Blomberg B, Spinaci S, Fourie B, Laing R (2001) The rationale for recommending fixed-dose combination tablets for treatment of tuberculosis. Bull World Health Organ 79: 61-68

16. Fountoulakis KN, Gazouli M, Kelsoe J, Akiskal H (2015) The pharmacodynamic properties of lurasidone and their role in its antidepressant efficacy in bipolar disorder. European Neuropsychopharmacology 25: 335-342.

17. World Medical Association Declaration of Helsinki (2008) 59th General Assembly Seoul, Korea.

18. http://www.fda.gov/Drugs/GuidanceCompliance Regulatory Information/ Guidances.htm

19. Chae YJ, Koo TS, Lee KY (2012) A Sensitive and Selective LC-MS Method for the determination of lurasidone in rat plasma, bile, and urine. Chromatographia75: 1117-1128.

20. Koo TS, Kim SJ, Lee J, Ha DJ, Baek M et al. (2011) Quantification of lurasidone, an atypical antipsychotic drug, in rat plasma with highperformance liquid chromatography with tandem mass spectrometry. Biomed Chromatogr 25: $1389-1394$

21. Food and Drugs Administration (2009) Guidance for industry Statistical Approaches to Establishing Bioequivalence.

22. The European Agency for the Evaluation of Medicinal Products EMA (2001) Committee for Proprietary Medicinal Products (CPMP) Note for guidance on the investigation of Bioavailability and Bioequivalence, London.

23. Perry R (2010) Perspectives on the bioequivalence and therapeutic equivalence of generic formulations: An overview of the landscape. Clin Ther 32: 17961797.

24. WHO (2006) Technical Report series, Fortieth Report, Geneva 